\title{
ХИМИЧЕСКАЯ НАПРАВЛЕННОСТЬ УМА: К ВОПРОСУ О ВОЗМОЖНОСТИ ФОРМИРОВАНИЯ ПРЕДПРИНИМАТЕЛЬСКОЙ КУЛЬТУРЫ И ПОЗИЦИИ АКТИВНОГО ГРАЖДАНИНА ПРИ ИЗУЧЕНИИ ХИМИИ В СТАРШЕМ ПОДРОСТКОВОМ ВОЗРАСТЕ
}

\section{THE FOCUS OF THE MIND ON CHEMICAL PHENOMENA: THE QUESTION ABOUT THE OPPORTUNITY OF FORMING ENTREPRENEURIAL CULTURE AND THE POSITION OF AN ACTIVE CITIZEN WHEN STUDYING CHEMISTRY IN TEENADERS \\ I. Kibal'chenko}

Summary: The article is devoted to the study of the gap between the content of academic disciplines and the content of life in the aspect of entrepreneurial culture and the position of an active citizen of older adolescents. It was hypothesized that older adolescents with high academic performance in the study of disciplines such as chemistry, mathematics and others, in comparison with adolescents with low academic performance, will differ in the content of answers according to criteria such as elaboration, belonging of subject knowledge to universal or special in the aspect of entrepreneurial activity. It was found that knowledge in chemistry as a special one in combination with an open cognitive position is one of the prerequisites for a modern entrepreneur. Research prospects lie in the design of a developing, enriched educational environment aimed at developing the chemical orientation of the mind and chemical thinking of older adolescents.

Keywords: chemical intelligence, older teens, open cognitive position, entrepreneurial culture.
$\mathrm{O}$ дним из дефектов современного образования, существенно снижающим ментальные ресурсы человека, является разрыв, между содержанием того, чему и как мы учим, и содержанием жизни [3]. В связи с этим все актуальнее становится изучение и внешних ресурсов (развитие промышленности, информационных технологий, высокотехнологичной экономики; развитие предпринимательства, образования и т.д.), и внутренних (человеческий потенциал, интеллектуальные и личностные особенности; способности) [7]. Объединение этих ресурсов - одно из основных условий успешности и каждого члена общества, и всей страны. Анализируя проблему предпринимательства, можно сказать, что его кристаллизующим фактором является объединение внешних и внутренних ресурсов. Обнаруженные в исследованиях [4] противоречия между выра-
Кибальченко Ирина Александровна

Д.ncх.н., профессор, Южный федеральный университет kibal-irina@mail.ru

Аннотация: Статья посвящена изучению разрыва содержания учебных дисциплин и содержания жизни в аспекте предпринимательской культуры и позиции активного гражданина старших подростков. Была выдвинута гипотеза о том, что старшие подростки с высокой успеваемостью при изучении таких дисциплин, как химия, математика и другие, в сравнении с подростками с низкой успеваемостью, будут отличаться содержанием ответов по таким критериям, как разработанность, принадлежность предметных знаний к универсальным или специальным в аспекте предпринимательской деятельности. Получено, что знания по химии как специальные в совокупности с открытой познавательной позицией - одна из предпосылок современного предпринимателя.

Перспективы исследования состоят в конструировании развивающей, обогащенной образовательной среды, направленной на развитие химической направленности ума и химического мышления старших подростков.

Ключевые слова: химические способности, химическая направленность ума, старшие подростки, открытая познавательная позиция, предпринимательская культура. женным интересом молодежи к предпринимательству, готовностью и конкретными действиями в этой области, обусловлены наличием или отсутствием у молодежи предпринимательских способностей [5]. В структуре предпринимательских способностей выделяют такие характеристики, как гибкость мышления, креативность, готовность преодолевать трудности и другие. Изучение и развитие предпринимательской культуры и способностей у старших подростков может стать предиктором интеграции их внутренних ресурсов и внешних, формирования открытой познавательной и гражданской позиции, интеллектуального инструмента деятельности, посредством наделения системы своих способностей и знаний, интересов и достижений страны ресурсной ролью и значимостью. 
В подростковом возрасте активно и плодотворно развиваются базовые элементы интеллектуально-личностного ресурса: развитие познавательных процессов и познавательной активности, способности к гипотетико-дедуктивным рассуждениям (стадия формальных операций по Ж. Пиаже), способности логически мыслить; становление феномена теоретизирования; развитие понятийного мышления, на основе чего «интеллектуализируются» все психические функции; становление избирательности, целенаправленности восприятия, развитие самостоятельного мышления, интеллектуальной активности, творческого подхода к решению задач; понятийного мышления как предиктора развития личностной рефлексии и «интеллекта взрослого типа»; развитие познавательной мотивации, эмоциональной устойчивости, самостоятельности, самоконтроля и ответственности [6]. Интеллектуально-личностный ресурс подростков, признаки их предпринимательской культуры и способностей с учетом тенденций в развитии новых технологий и качества жизни человека находят свое отражение в выборе дисциплин при подготовке к ЕГЭ.

Часто и устойчиво учащиеся выбирают биологию, иностранный и русский язык, математику, обществознание, физику, историю. Однако появилась тенденция к выбору ими дисциплин естественно-научного цикла, в том числе и химии. Тенденция, на наш взгляд, обусловлена тем, что знания по химии необходимы для освоения специальностей в области медицины, биологии, геологии, добычи нефти и газа, косметологии, химии, экологии и других. Химическая направленность ума подрастающего поколения как способность выделять из окружающего мира химические явления и закономерности, способность использовать их в реальной жизни, обусловливает выбор объектов инновационной научной и предпринимательской деятельности, в том числе и производств новых медицинских препаратов.

Не смотря на значимость базовой химической грамотности учащихся для развития предпринимательской культуры, уровень химической грамотности падает. Выявленные факты обусловливают необходимость изучения предпосылок формирования предпринимательской культуры и позиции активного гражданина у подростков в аспекте их базовых знаний.

\section{Организашия исследования}

Выборку исследовании составили подростки - учащиеся восьмых классов общеобразовательных школ Ростовской области (74 человека, средний возраст - 15 лет).

В процессе эмпирического исследования проводился экспресс-опрос с целью выявления отношения подростков к предпринимательской деятельности. В связи С этим подросткам предлагались открытые вопросы:

Как вы относитесь к предпринимательству?

Какие знания Вы бы использовали как современный предприниматель?

Технологически эта процедура включала дифференциацию своих знаний математике, информатике, иностранному и русскому языку, физике и химии на «специальные» или «универсальные». Ответ необходимо обосновать.

Для диагностики познавательной позиции подростков использовалась методика М.А. Холодной «Идеальный компьютер».

\section{Результаты исследования}

В эмпирическом исследовании были использованы результаты подростков с высокой успеваемостью (20 человек со средним баллом успеваемости - 4,8) с открытой познавательной позицией; подростки с низкой успеваемостью (25 человек средним баллом успеваемости - 3,2) и закрытой познавательной позицией.

Были выдвинуты предположения:

- подростки с высокой успеваемостью, в сравнении с подростками с низкой успеваемостью, будут отличаться по таким критериям, как разработанность; достижения в образовательных областях (информатика, иностранный и русский язык, математика, физика как универсальные для предпринимательства);

- подростки с высокой успеваемостью, в сравнении с подростками с низкой успеваемостью, будут отличаться доминированием выбора знаний по химии как специальных для предпринимательской деятельности.

Результаты исследования, полученные в группах старшеклассников, представлены в таблицах 1 и 2.

Результаты, представленные в таблице 1, свидетельствуют о том, что в группе подростков с высокой успеваемостью и открытой познавательной позицией классификация предметных знаний как универсальных и специальных - следующая: к специальным они значимо чаще $(p \leq 0,01)$ относят знания и умения по химии (с биологией); к универсальным они значимо чаще относят знания по информатике, иностранному языку, математике $(p \leq 0,01)$, по физике $(p \leq 0,05)$.

Они обосновывают свой выбор тем, что такие современные профессии, как биохимик, врач, диетолог, нано-технолог, химик-технолог, химик-эколог, химиккосметолог, эксперт продуктов питания, прежде всего, связаны со знаниями по химии. Актуализация химиче- 
Таблица 1.

Результаты старшеклассников с высокой успеваемостью и открытой познавательной позицией

\begin{tabular}{|c|c|c|c|c|}
\hline Вопросы & \multicolumn{4}{|c|}{ Ответы } \\
\hline \multirow{2}{*}{$\begin{array}{l}\text { Как вы относитесь к } \\
\text { предпринимательству? }\end{array}$} & Положительно & Отрицательно & Трудно ответить & Статистические различия \\
\hline & 15 чел. - 75\% & 5 чел. $-25 \%$ & $0-0 \%$ & $\begin{array}{c}\varphi^{*} \text { эмп. }=3,31 \geq \varphi^{*} \text { кр. }=2,31 \\
p \leq 0,01\end{array}$ \\
\hline Какие знания Вы бы & \multicolumn{4}{|c|}{ В ответах выделены знания } \\
\hline $\begin{array}{l}\text { использовали как современный } \\
\text { предприниматель? }\end{array}$ & «Специальные» & «Универсальные» & Трудно ответить & Статистические различия \\
\hline Знания по химии (с биологией) & $17-85 \%$ & $0-0 \%$ & $3-15 \%$ & $\varphi^{*}$ эМП. $=4,91, p \leq 0,01$ \\
\hline Знания по физике & $7-35 \%$ & $13-65 \%$ & $0-0 \%$ & $\varphi^{*} \ni$ мп. $=1,93, p \leq 0,05$ \\
\hline Знания по математике & $3-15 \%$ & $17-85 \%$ & $0-0 \%$ & $\varphi^{*} э$ мп. $=4,91, p \leq 0,01$ \\
\hline Знания по информатике & $3-15 \%$ & $17-85 \%$ & $0-0 \%$ & $\varphi^{*}$ эмп. $=4,91, p \leq 0,01$ \\
\hline Знания по иностранному языку & $2-10 \%$ & $18-90 \%$ & $0-0 \%$ & $\varphi^{*} \ni$ МП. $=5,86, p \leq 0,01$ \\
\hline Знания по русскому языку & $5-25 \%$ & $8-40 \%$ & $7-35 \%$ & Нет различий \\
\hline
\end{tabular}

Таблица 2

Результаты старшеклассников с низкой успеваемостью и закрытой познавательной позицией

\begin{tabular}{|c|c|c|c|c|}
\hline Вопросы & \multicolumn{4}{|c|}{ Ответы } \\
\hline \multirow{3}{*}{$\begin{array}{l}\text { Как вы относитесь к } \\
\text { предпринимательству? }\end{array}$} & Положительно & Отрицательно & Трудно ответить & Различия \\
\hline & $14-56 \%$ & & $8-32 \%$ & $\varphi^{*} \ni$ мп. $=4,41, p \leq 0,01$ \\
\hline & $14-56 \%$ & $3-12 \%$ & & $\varphi^{*}$ эмп. $=4,11, p \leq 0,01$ \\
\hline \multirow{2}{*}{$\begin{array}{l}\text { Какие знания Вы } \\
\text { бы использовали } \\
\text { как современный } \\
\text { предприниматель? }\end{array}$} & \multicolumn{4}{|c|}{ В ответах выделены знания } \\
\hline & «Специальные» & «Универсальные» & Трудно ответить & Различия \\
\hline $\begin{array}{l}\text { Знания по химии } \\
\text { (сбиологией) }\end{array}$ & $2-8 \%$ & $2-8 \%$ & $21-84 \%$ & $\varphi^{*}$ эмп. $=6,59, p \leq 0,01$ \\
\hline \multirow[t]{2}{*}{ Знания по физике } & $8-32 \%$ & & $12-48 \%$ & Нет различий \\
\hline & & $5-20 \%$ & $12-48 \%$ & $\varphi^{*}$ эмп. $=2,47, p \leq 0,01$ \\
\hline \multirow[t]{2}{*}{ Знания по математике } & $4-16 \%$ & & $14-56 \%$ & $\varphi^{*}$ эмп. $=3,54, p \leq 0,01$ \\
\hline & & $7-28 \%$ & $14-56 \%$ & $\varphi^{*} э$ мп. $=2,21, p \leq 0,05$ \\
\hline \multirow[t]{2}{*}{ Знания по информатике } & $3-12 \%$ & & $15-60 \%$ & $\varphi^{*} э$ мп. $=4,37, p \leq 0,01$ \\
\hline & & $7-28 \%$ & $15-60 \%$ & $\varphi^{*}$ эмп. $=2,47, p \leq 0,01$ \\
\hline \multirow{2}{*}{$\begin{array}{l}\text { Знания по иностранному } \\
\text { языку }\end{array}$} & $3-12 \%$ & & $13-52 \%$ & $\varphi^{*}$ эмп. $=3,82, p \leq 0,01$ \\
\hline & & $9-36 \%$ & $13-52 \%$ & Нет различий \\
\hline \multirow[t]{2}{*}{ Знания по русскому языку } & $11-44 \%$ & & $2-8 \%$ & $\varphi^{*}$ эмп. $=3,89, p \leq 0,01$ \\
\hline & & $12-48 \%$ & $2-8 \%$ & $\varphi^{*}$ Эмп. $=4,21, p \leq 0,01$ \\
\hline
\end{tabular}

ской направленности ума с целью предпринимательства эффективна в совокупности со знаниями по математике, информатике и иностранному языку.

Такая система знаний и открытой познавательной позиции расширяет и профессиональные, и научные, и территориальные границы для молодых людей, является предиктором формирования предпринимательской культуры и позиции активного гражданина.

Рассмотрим результаты подростков с низкой успеваемостью и закрытой познавательной позицией (Таблица 2).

Результаты, представленные в таблице 2, свидетельствуют о том, что в группе подростков с низкой успевае- 
мостью и закрытой познавательной позицией возникли затруднения в наделении своих знаний значимой ролью в аспекте своего будущего. Они уверены лишь относительно значимости знаний по русскому языку $(\mathrm{p} \leq 0,01)$, однако мнение о значимости знаний по иностранному языку, математике, физике и химии у них не сформировано.

Анализируя результаты подростков этой группы, возникает противоречие между их положительным отношением к предпринимательству и незначимостью знаний для своего будущего. Вероятно, поэтому и обоснования ответов не убедительные: для работы нужны разные знания; чтобы считать, математика, все могут хорошие компьютерные программы. Значимость знаний по иностранному языку отмечается только в плане взаимодействия с людьми из других стран. Представленные подростками этой группы обоснования своих ответов, на наш взгляд, нельзя рассматривать как предпосылки развития позиции активного гражданина и успешного предпринимателя.

\section{Зак^ючение}

Обращаясь к проблеме разрыва содержания учебных дисциплин и содержания жизни, необходимо отметить, что формирование предпринимательской культуры и позиции активного гражданина при изучении химии невозможно без формирования химической направленности ума - одного из оснований развития специальных химических способностей.

Химическая направленность ума - это способность выделять из окружающего мира химические явления, химические закономерности и использовать их в реальной жизнедеятельности. Именно химическая направленность ума определяет выбор объекта предпринима- тельской деятельности и инновационность процессов его производства. Особенностью химической направленности ума является то, что предметное содержание химии может быть зримым, вещественным, осязаемым, оно затрагивает всю сенсорно-перцептивную организацию человека. Как отмечает Е.В. Волкова, химическая направленность ума - это не только «ощущение материи», это и еще особый интерес к составу, свойствам и превращениям веществ. Это способность на основе сенсорно-перцептивной информации реконструировать микромир химических взаимодействий, и опираясь на умственные модели, фиксирующие особенности тех или иных химических взаимодействий, воссоздавать ту или иную сенсорно-перцептивную информацию [1, 2].

Анализируя полученные результаты с позиции преподавания химии в общеобразовательных школах, следует отметить, что, несмотря на значимый рост интереса старшеклассников к естественно-научным дисциплинам, в том числе и к химии, наблюдается снижение базовой химической грамотности у учащихся. Это противоречие, с одной стороны, определяет задачу формирования у старших подростков химического мышления (химических способностей), обусловливающих творческую реализацию учащихся в области химии: способность выделять характеристики химических объектов, сопоставлять их по различным основаниям, понимать закономерности и механизмы химических процессов, выдвигать авторские идеи и проекты в области химии. С другой стороны - ставит задачу изменения содержания химического образования в направлении формирования предпринимательской культуры на базе инновационных учебных текстов и технологий.

Исследование выполнено при поддержке Российского фонда фундаментальных исследований (проект № 1929-14019), Институт психологии РАН.

\section{ЛИТЕРАТУРА}

1. Волкова Е.В. Химическая направленность ума // Химия в школе. 2008. № 2. С. 2-7.

2. Волкова Е.В. Психология специальных способностей: дифференционно-интеграционный подход. М.: Изд-во Институт психологии РАН, 2011.

3. Волкова Е.В. Технологии развития ментальных ресурсов. М.: Изд-во Институт психологии РАН, 2016.

4. Джанерьян С.Т., Солдатова, И.А. Психологическая готовность студентов-выпускников ЮФУ к предпринимательской деятельности // Наука и образование: хозяйство и экономика; предпринимательство; право и управление. - 2012. - № 2 (21). - С. 12-17.

5. Кибальченко И.А., Эксакусто Т.В. Дескрипторы успешной предпринимательской деятельности/ Социально-гуманитарные исследования и технологии. 2016. T. 5. №. 3. - C. 41-46.

6. К Князева Т.Н. Современные аспекты проблемы интеллектуального развития подростков в период возрастного кризиса // Современные проблемы науки и образования. - 2014. - № 6.; URL: http://www.science-education.ru/ru/article/view?id=16562 (дата обращения: 20.09.2019).

7. Exakusto Tatiana V., Kibalchenko Irina A., Kompaniets Vitaly S. Personality Profiles of Young People-Potential Entrepreneurs // Mediterranean Journal of Social Sciences. Vol 6, № 3 S2. 2015. P. 640-649. 